\title{
Study the Effect of Recycled Tire Rubber on the Mechanical and Rheological Properties of TPV (HDPE/Recycled Tire Rubber)
}

\author{
Ziyad T. Al-Malki ${ }^{1}$, Einas A. Al-Nasir ${ }^{1}$, Moayad N. Khalaf ${ }^{2 *}$, Raed K. Zidan ${ }^{2}$ \\ ${ }^{1}$ Department of Chemical and Technology of Polymer, Polymer Research Centre, University of Basrah, Basrah, Iraq \\ ${ }^{2}$ Department of Chemistry, College of Science, University of Basrah, Basrah, Iraq \\ Email: *Moayad.Khalaf@uobasrah.edu.iq
}

Received August 10, 2013; revised September 10, 2013; accepted September 18, 2013

Copyright (C) 2013 Ziyad T. Al-Malki et al. This is an open access article distributed under the Creative Commons Attribution License, which permits unrestricted use, distribution, and reproduction in any medium, provided the original work is properly cited.

\begin{abstract}
Thermoplastic elastomeric blends were prepared from blending of $(10 \%, 20 \%, 30 \%, 40 \%$ and 50 wt $\%)$ high density polyethylene(HDPE) and $(10 \%, 20 \%, 30 \%, 40 \%$ and $50 \mathrm{wt} \%)$ ground rubber tire (TPV-R). The blends prepared contain (HDPE)/polybutadiene (TPV-V). The two blends were successfully prepared through a dynamic vulcanization process, involving dicumyl peroxide (3\%) as vulcanizing agent. The data of the mechanical (tensile strength at yield, \%elongation and young modulus) and rheological properties (shear stress, shear rate, viscosity, flow behavior index and activation energy of melt flow) of the TPV-V and TPV-R showed that there were comparable results between the two blends.
\end{abstract}

Keywords: Thermoplastic Vulcanized Rubber; Rubber Recycling; Mechanical Properties

\section{Introduction}

In recent decades, improved properties of polymer mixtures such as thermal stability impact resistance, flame retardant, ductility and stiffness etc. had paved the development of blending of polymer mixtures. The total market volume for polymer blends is currently estimated to be more than 1.1 million metric tons a year [1]. It includes a significant number of large volume products such as PPE/HIPS blends (Norly (R)), PC/PBT blends (Xenoxy), and PA/PPE blends (Noryl GTX) [2,3] etc. which are being generated to equip the multipurpose needs of plastics industry. One of the growing challenges to the environment pollution was the rubber polymer because not only in industrialized countries but also in less developed nations, rubber products are everywhere to be found, though few people recognize rubber in all of its applications. Since 1920, demand for rubber manufacturing has been largely dependent on the automobile industry, the biggest consumer of rubber products. Rubber is used in radio and T.V sets and in telephones. Electric wires are made safe by rubber insulation. Rubber forms a part of many mechanical devices in the kitchen. It helps to exclude draughts and to insulate against noise.

\footnotetext{
*Corresponding author.
}

Sofas and chairs may be upholstered with foam rubber cushions, and beds may have natural rubber pillows and mattresses. Clothing and footwear may contain rubber: e.g. elasticized threads in undergarments or shoe soles. Most sports equipment, virtually all balls, and many mechanical toys contain rubber in some or all of their parts. Still other applications have been developed due to special properties of certain types of synthetic rubber, and now there are more than 100,000 types of articles in which rubber is used as a raw material [4]. Recycling of polymeric wastes is an environmental problem of great concern especially the tire rubber [4]. The scrap of tire rubber discarded each year was very large volume, which was caused by the fast development of the automobile industry [5]. More than 17 million tons of rubber is used in the production of automobile tires. This is responsible for a vast amount of wastes. The different chemical compositions and the crosslinked structures of rubber in tires are the prime reason, that it was highly resistance to biodegradation, photochemical decomposition, chemical reagents and high temperatures. Therefore the serious threat to natural environment was the increasing numbers of used tires [6], which start to be perceived as a potential source of valuable raw materials. The most limited option was the processibility of the rubber. The blending 
of thermoplastic polymer like polyethylene has the ability to flow under certain conditions (supported usually by the action of heat and/or pressure), so that it can be shaped into products at acceptable cost [7]. This can be achieved using thermoplastics, thermosetting resins and rubber compounds as potential matrices. In this paper the effect of ground tire rubber (GTR) on the mechanical and rheological properties of thermoplastic vulcanized rubber (TPV-R) was compared with version rubber. The data show that TPV-V containing version rubber had better mechanical properties and less viscosity value than the TPV containing GTR.

\section{Experimental}

\subsection{Material}

High density polyethylene (HDPE) SCPILEX 6003 was supplied by state company for petrochemical industry $(\mathrm{SCPI})$ in Basra $(\mathrm{MFI}=6.0 \mathrm{gm} / 10 \mathrm{~min}$, density $=0.963$ $\mathrm{gm} / \mathrm{cm}^{3}$. Polybutadiene was obtained from Malaysian company with (Mooney viscosity ML $(1+4)$ at $100^{\circ} \mathrm{C}$ $45 \pm 5$ ). Dicumyl peroxide was supplied by Fluka company and use as it is. Ground tire rubber was obtained from scrap tires, which are first shredded into larger pieces (avarege size $20 \_20 \mathrm{~mm}$ ) and then ground to less than $1 \mathrm{~mm}$. Spikes, cords and textiles are subsequently removed.

\section{Instrument}

\subsection{Rheological Measurements}

Rheological properties were carried out by using a capillary rheometer device (Instron model 3211), according to ASTM D-3835. The diameter of the capillary is $0.76 \mathrm{~mm}$, the length to diameter (L/D) ratio of 80.9, with an angle of entry of $90^{\circ}$. Load weighing which dropped on the polymer melts by plunger transverse from the top to the bottom of the barrel was constant $(2000 \mathrm{~kg})$. The constant plunger speeds ranged from 0.06 to $20.0 \mathrm{~cm} \cdot \mathrm{min}^{-1}$ and the extrusion temperature was $180^{\circ} \mathrm{C}$.

\subsection{Mechanical Measurements}

The tensile testing measurements were performed with an Instron 1193 tensile machine at room temperature using dumbbell-shaped specimens (at least five specimens for each sample) as per ASTM D 638-5. The crosshead speed was $50 \mathrm{~mm} \cdot \mathrm{min}^{-1}$.

\subsection{Preparation of the Thermoplastic Vulcanized (TPV-GTR) and (TPV-P)}

Mixer-600 attached to Haake Rhechard Torque Rheometer supplied by Haake Company was used for the preparation of the TPV. The total weight of the (HDPE/Rub- ber) was 60 gm. GTR or Polybutadiene in the percent $(0 \%, 10 \%, 20 \%, 30 \%, 40 \%, 50 \%, 60 \%, 70 \%, 80 \%$ and $90 \mathrm{wt} \%)$ was feed to Mixer-600 at temperature $=140^{\circ} \mathrm{C}$ and $\mathrm{RPM}=32$. After 2 min. of mixing the high density polyethylene was added and continue mixing for $5 \mathrm{~min}$. Then the dicumyl peroxide (3\%) was added and the velocity of mixing was changed to RPM $=64$ and the mixing time continue for $10 \mathrm{~min}$.

\section{Result and Discussion}

\subsection{Mechanical Properties}

The mixture of the HDPE and rubber (GTR and BP) blends have good mechanical properties $[9,10]$. Figures $\mathbf{1}$ and $\mathbf{2}$ show the tensile strength and Young's modulus of the TPV-P and TPV-R blends. It can be seen with increasing the rubber content the tensile strength of both TPV-R and TPV-P was decreased, this can be attributed to the rubber content. The elastomer phase remains as dispersed particles in the TPV-R and TPV-P blends and the HDPE was bearing the tensile force applied on the blends which is in agreement with previous work [11]. While the higher value of tensile strength and Young's

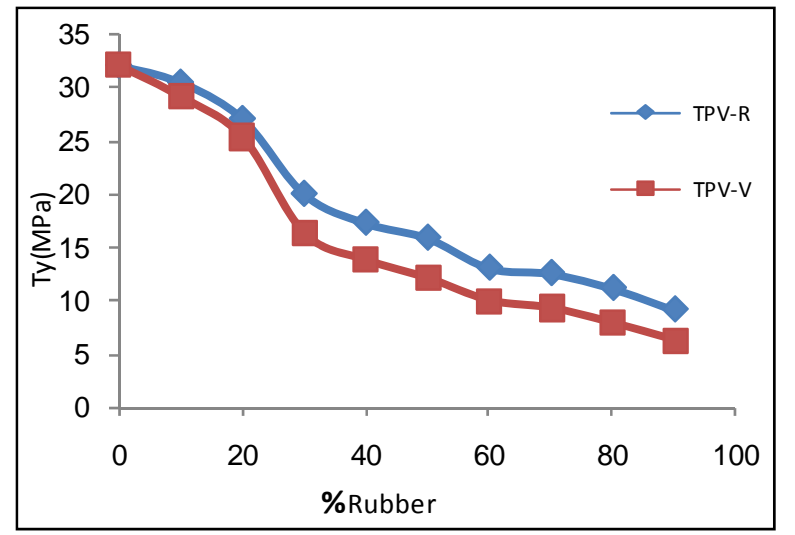

Figure 1. Effect of \% polyethylene on the tensile strength at yield of TPV-V and TPV-R.

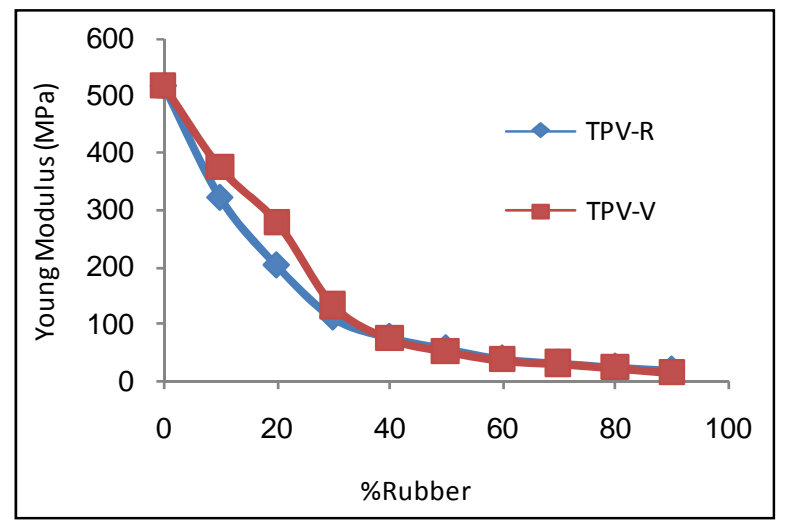

Figure 2. Effect of $\%$ rubber on the young modulus of TPV-V and TPV-R. 
modulus of TPV-R and TPV-P blends were due to the smaller size and uniform dispersion of the dispersed phase. Agglomeration and particle-particle interaction of the rubber powder were observed decrease in tensile strength and Young's modulus of TPV-P and TPV-R blends. The reduction of tensile strength and Young's modulus value of TPV-R and TPV-P may be due to decreasing of the blend rigidity. This is a common observation since many researchers $[12,13]$ also reported similar findings. However, at a similar rubber content, tensile strength and Young's modulus of TPV-R blends are slightly higher than TPV-P blends. In TPV-P blends, the molecular entanglements in the rubber chains alone are insufficient to prevent rapid flow and fracture in response to the applied stress. This results in the lower tensile strength and Young's modulus of the HDPE/PB blend. For HDPE/GTR blends, the presence of the crosslinking rubber powder and others curatives in GTR has allowed the rubber particles to reach higher strains and at the same time confers mechanical strength to the particles [11].

Figure 3 shows the variation of elongation at break, $\mathrm{Eb}$ (\%elongation at break) for TPV-R and TPV-Pblends, respectively. It can be seen that for both blends, Eb increases with increasing rubber content due to the elasticity of rubber. However, at a similar rubber content, $\mathrm{Eb}$ for TPV-P the blend is higher than TPV-R blend. Again this observation is due to the presence of crosslinking rubber particles and other ingredients in GTR which limit the flow and mobility of the TPV-R blend [11].

\subsection{Rheological Properties}

Rheological behavior of polymeric melts is an important aspect to understand the flow behavior of the materials during processing. Capillary rheometry is the most common technique used to determine deformation of polymeric melt under shear flow [14]. The polymer standard flow curve (shear stress vis. Shear rate) was divided to

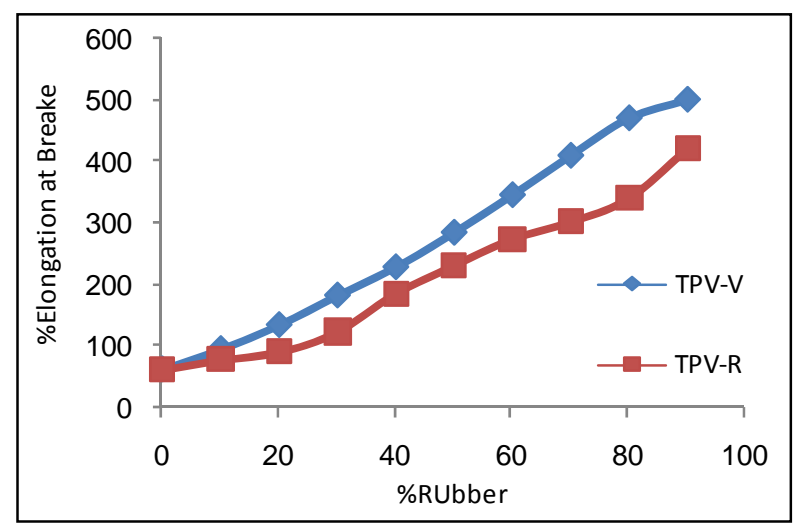

Figure 3. Effect of \% rubber on the \%elongation at break of TPV-V and TPV-R. four regions as shown in Figure 4. The addition of vulcanizing agent improves the (HDPE/Rubber) properties of the blend substantially [15]. Figure 5 show the flow curves (shear stress vis. shear rate) for TPV-R and TPV-V, From the figure it was seen that the curves was smooth and linear and there was no discontinuity in the flow curves in the four region of the standard flow curve as seen in Figure 5 with the value of shear stress for the TPV-R higher than the TPV-V. The higher value for the TPV-R because the GTR chain was already crosslinked and the TPV-R (HDPE/GTR crosslinking) will be randomly oriented and entangled chains, for that this will restricted the chains to become oriented and disentangled more that the TPV-V(HDPE/BP) [16].

The variation of melt viscosity as a function of shear rate for TPV-R and TPV-V blends at $180^{\circ} \mathrm{C}$ are shown in Figure 6. The melt viscosity decreased with increasing shear rate (Figure 6) indicating the pseudoplastic nature of the blends. Hence, processability is improved. At $180^{\circ} \mathrm{C}$, the viscosity of TPV-R was higher than TPV-V. The presence of the GTR which was already vulcanized limited the TPV-R chain to be oriented leads to an increase in the melt viscosity due to the greater resistance they offer to flow [15]. The activation energy (Ea) of the flow process was calculated from the slope of $\log \eta$ versus $1 / \mathrm{T}$ using the Arrhenius type of equation [16].

$$
\eta=\mathrm{A} e^{E a / R T}
$$

where $\eta$ is the melt viscosity, A is a pre-exponential factor, $E a$ the activation energy, $T$ the temperature $(\mathrm{K})$, and $R$ the universal gas constant $\left(8.314 \mathrm{~J} \mathrm{~K}^{-1} \cdot \mathrm{mol}^{-1}\right)$. The activation energy of flow is the minimum energy required for the molecules to just flow which is equivalent to energy necessary to overcome the intermolecular forces of attraction as well as the resistance due to the entanglements [17]. The variation of Ea (Table 1) could be attributed to the change in the morphology under shear deformation [18]. Ea decreased with increasing shear rate for both TPV-R and TPV-V blends, probably due to the strong shear thinning behavior. However, the TPV-R had higher Ea than TPV-V, indicate that the TPV-R had less vulcanization between HDPE and GTR, which increases chain mobility and activation energy [16].

Table 1. Variation of the activation energy $(\mathrm{kJ} / \mathrm{mol})$ at different shear rates 5.4, 18, 54, 180, 540 and $1800 \mathrm{~s}^{-1}$.

\begin{tabular}{ccccccc}
\hline \multirow{2}{*}{$\begin{array}{c}\text { Type } \\
\text { of }\end{array}$} & \multicolumn{5}{c}{ Shear Rate } \\
\cline { 2 - 6 } TPV & $5.4 \mathrm{~s}^{-1}$ & $18 \mathrm{~s}^{-1}$ & $54 \mathrm{~s}^{-1}$ & $180 \mathrm{~s}^{-1}$ & $540 \mathrm{~s}^{-1}$ & $1800 \mathrm{~s}^{-1}$ \\
\cline { 2 - 7 } Activation Energy (KJ/mol) \\
\hline HDPE & 26.25 & 10.97 & 4.6 & 1.76 & 0.58 & 0.21 \\
TPV-V & 31.11 & 12.4 & 5.55 & 2.05 & 0.77 & 0.29 \\
TPV-R & 37.03 & 15.3 & 5.9 & 2.3 & 0.94 & 0.32 \\
\hline
\end{tabular}




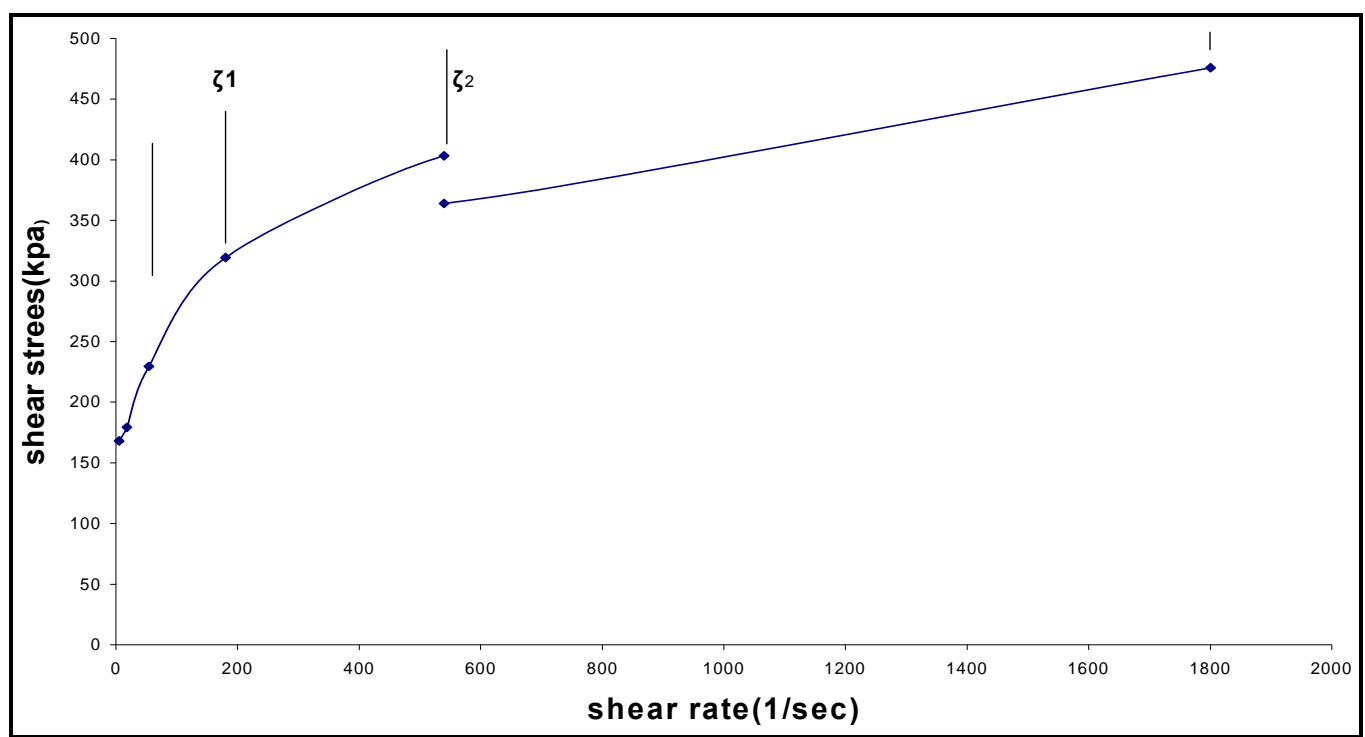

Figure 4. Standard flow curve for the polymer ( $\tau_{1}=$ first critical shear stress and $T_{2}=$ second critical shear stress).

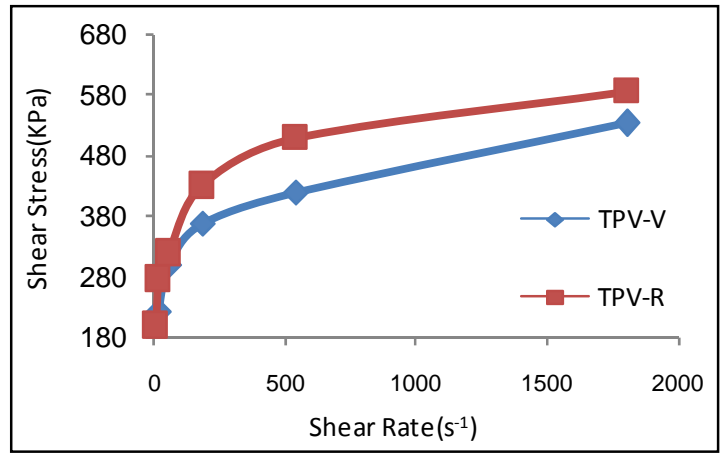

Figure 5. Variation of shear stress with shear rate for TPV-V and TPV-R (70Rubber/30HDPE) at $180^{\circ} \mathrm{C}$.

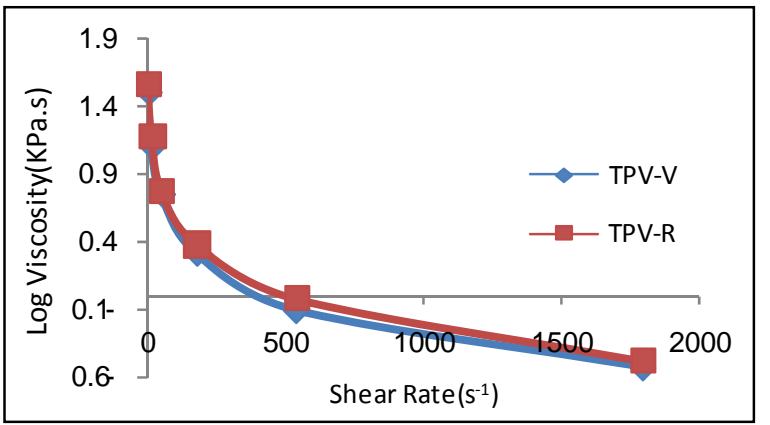

Figure 6. Variation of viscosity with Shear Rate for TPV-V and TPV-R (70Rubber/30HDPE) at $180^{\circ} \mathrm{C}$.

The flow behaviour index gives an idea about the nature of flow, i.e., whether it is Newtonian or non-Newtonian. Most polymers show pseudoplastic behavior with flow behavior index $\mathrm{n}$ less than 1 . The power-law equation was applied to describe the rheological behavior of the system. The melt flow behavior can be described by power law, which is expressed by Ostwald and de Waele model. The equation for this model is given as follows:

$$
\tau=K \gamma^{n}
$$

or

$$
\eta=K^{\gamma n-1}
$$

where $K$ reflects the consistency index of the polymer melt, with higher values representative of more viscous materials, and $n$ is the power-law index giving a measure of the pseudoplasticity. From (Table 2) the values of (n) obtaining among vulcanized HDPE/GTR and HDPE/BP blends do not differ very much from pure HDPE value , such behavior was reported by George et al. [19] and Oomenn et al. [20], and they indicated that the addition of up to $20 \%$ of rubber does not affect markedly the flow behavior of polypropylene. And here it was found that the addition of $30 \%$ of GTR or PB also does not affect markedly the flow behavior of HDPE. The consistency index (K) of the TPV-R (contain GTR) higher than the TPV-V (contain PB). The consistency index represents the viscosity at unit rate of shear. This indicates that the free volume of the system decreases, so the $K$-value increases.

\section{Conclusion}

From the above results it was indicated that the GTR (recycled tyre rubber) was comparable to the pure rubber and it can be used in many applications, which will be one way to control the environmental pollution by the large quantity of used rubber. The mechanical properties of the TPV-R which contain the GTR show comparable data with the TPV-P which contain PB. Both blends show the same behavior. The tensile strength, young modulus increases and \%elongation decreases with the increase of the percent of rubber in the TPV-R or TPV-V. 
Table 2. Flow behavior index $(n)$ and consistency index $(K)$.

\begin{tabular}{ccc}
\hline Property & $K$ & $n$ \\
\hline HDPE & 3.016 & 0.198 \\
TPV-V & 4.85 & 0.194 \\
TPV-R & 5.039 & 0.168 \\
\hline
\end{tabular}

While rheological behavior of TPV-R and TPV-V blends was investigated. It was found that both blends show pseudoplastic. Melt viscosity of TPV-R and TPV-V blends was sensitive to shear rates. Activation energies decreased with increasing shear rate for both TPV-R and TPV-V blends, probably due to the strong shear thinning behavior. The values of (n) obtaining among vulcanized HDPE/GTR and HDPE/BP blends do not differ very much from pure HDPE value. And it was found that the addition of $30 \%$ of GTR or PB also does not affect markedly the flow behavior of HDPE which was comparable with the data found in previous work with $20 \%$ rubber. The consistency index $(\mathrm{K})$ of the TPV-R (contain GTR) is higher than the TPV-V (contain PB), which indicating that the free volume of the system decreases, so the $K$-value increases.

\section{REFERENCES}

[1] A. Fainleib and O. Grigoryeva, "Recent Developments in Polymer Recycling," Chapter 6, Academic Press, Waltham, 2011.

[2] L. A. Utracki and B. D. Favis, "Polymer Alloys and Blends," In: P. N. Cheremisinoff, Ed., Handbook of Polymer Science and Technology, Marcel Dekker Inc, New York, 1989, pp. 121-201.

[3] L. M. Robeson, "Polymer Blends: A Comprehensive Review," Hanser Gardner, Munich, 2007. http://dx.doi.org/10.3139/9783446436503

[4] A. Fainleib and O. Grigoryeva, "Recent Developments in Polymer Recycling," Chapter 2, Academic Press, Waltham, 2011.

[5] H. S. Liu, J. L. Mead and R. G. Stacer, "Environmental Effects of Recycled Rubber in Land-Fill Applications," Rubber Chemistry \& Technology, Vol. 73, No. 3, 2000, pp. 551-564. http://dx.doi.org/10.5254/1.3547605

[6] M. Magioli, A. S. Sirqueira and B. G. Soares, "The Effect of Dynamic Vulcanization on the Mechanical, Dynamic Mechanical and Fatigue Properties of TPV Based on Polypropylene and Ground Tire Rubber," Polymer Testing, Vol. 29, No. 7, 2010, pp. 840-848. http://dx.doi.org/10.1016/j.polymertesting.2010.07.008

[7] M. Sienkiewicz, J. Kucinska-Lipka, H. Janik and A. Balas, "Progress in Used Tyres Management in the European Union: A Review," Waste Management, Vol. 32, No. 10, 2012, pp. 1742-1751. http://dx.doi.org/10.1016/j.wasman.2012.05.010

[8] D. Mangaraj, "Role of Compatibilization in Recycling Rubber Waste by Blending with Plastics," Rubber Chemistry \& Technology, Vol. 78, No. 3, 2005, p. 536.
[9] S. L. Zhang, Z. X. Zhang, K. Pal , Z. X. Xin, J. Suh and J. K. Kim, "Prediction of Mechanical Properties of Waste Polypropylene/Waste Ground Rubber Tire Powder Blends Using Artificial Neural Networks," Materials and Design, Vol. 31, No. 8, 2010, pp. 3624-3629. http://dx.doi.org/10.1016/i.matdes.2010.02.039

[10] Z. Hrdlick, A. Kuta and J. Hajek, "Preparation Thermoplastic Elastomer Blends Based on Waste Rubber and LowDensity Polyethylene," Polimery, Vol. 55, No. 11-22, 2010, pp. 832-838.

[11] H. Ismail and Suryadiansyah, "Thermoplastic Elastomers Based on Polypropylene/Natural Rubber and Polypropylene/Recycle Rubber Blends," Polymer Testing, Vol. 21, No. 4, 2002, pp. 389-395.

http://dx.doi.org/10.1016/S0142-9418(01)00101-5

[12] H. Ismail and L. Mega, "The Effect of a Compatabilizer and a Silane Coupling Agent on the Mechanical Properties of White Rice Husk and Ash Filled Polypropylene/ Natural Rubber Blend," Polymer Plastics Technology and Engineering, Vol. 40, No. 4, 2001, pp. 463-478. http://dx.doi.org/10.1081/PPT-100002070

[13] H. Ismail, M. N. Nasaruddin and U. S. Ishiaku, "White Rice Husk Ash Filled Natural Rubber Compounds: The Effect of Multifunctional Additive and Silane Coupling Agents," Polymer Testing, Vol. 18, No. 4, 1999, pp. 287298. http://dx.doi.org/10.1016/S0142-9418(98)00030-0

[14] N. Sombatsompop and R. Dangtungee, "Effects of the Actual Diameters and Diameter Ratios of Barrels and Dies on the Elastic Swell and Entrance Pressure Drop of Natural Rubber in Capillary Die Flow," Journal of Applied Polymer Science, Vol. 86, No. 7, 2002, pp. 17621772. http://dx.doi.org/10.1002/app.11212

[15] A. Y. Coran and R. P. Patel, "Thermoplastic Elastomers," 3rd Edition, Hanser Publishers, Munich, 2004.

[16] M. Hernandez, J. Gonzalez, C. Albano, M. Ichazo and D. Lovera, "Effects of Composition and Dynamic Vulcanization on the Rheological Properties of PP/NBR Blends," Polymer Bulletin, Vol. 50, No. 3, 2002, pp. 205-212. http://dx.doi.org/10.1007/s00289-003-0158-8

[17] R. Wagener and T. J. G. Reisinger, "A Rheological Method to Compare the Degree of Exfoliation of Nanocomposites," Polymer, Vol. 44, No. 24, 2003, pp. 7513-7518. http://dx.doi.org/10.1016/j.polymer.2003.01.001

[18] J. S. Borah and T. K. Chaki, "Effect of Organo-Montmorillonite Addition on the Dynamic and Capillary Rheology of LLDPE/EMA Blends," Applied Clay Science, Vol. 59-60, 2012, pp. 42-49. http://dx.doi.org/10.1016/j.clay.2012.02.007

[19] S. George, R. Joseph, S. Thomas and K. T. Varughese, "Molecular Transport of Aromatic Solvents in Isotactic Polypropylene/Acrylonitrile-Co-Butadiene Rubber Blends," Polymer, Vol. 36, No. 23, 1995, pp. 4405-4416. http://dx.doi.org/10.1016/0032-3861(95)96846-Z

[20] Z. Oommen, S. Thomas, C. K. Premalatha and B. Kuriakose, "Melt Rheological Behaviour of Natural Rubber/ Poly(methyl methacrylate)/Natural Rubber-g-poly(methyl methacrylate) Blends," Polymer, Vol. 38, No. 22, 1997, pp. 5611-5621.

http://dx.doi.org/10.1016/S0032-3861(97)00120-1 